\title{
INDUKSI PEMBUNGAAN Mucuna bracteata MENGGUNAKAN PAKLOBUTRAZOL DENGAN SISTEM TANAM VERTIKAL
}

\author{
${ }^{1)}$ Kamsia Dorliana Sitanggang, ${ }^{2}$ Siti Hartati Yusida Saragih, ${ }^{3)}$ Khairul Rizal \\ Fakultas Sains dan Teknologi, Universitas Labuhanbatu \\ Rantau prapat, Indonesia \\ Email : ${ }^{1}$ kamsiasitanggang@gmail.com
}

\begin{abstract}
Mucuna bracteata one of Legume Cover Crop many used in plantation. Mucuna bracteata can not flowering naturally. The objective of this research is to induce flowering Mucuna bracteata through paclobutrazol treatment with verticulture system. The methods are : induce shortly vegetative fase, count of secondary adventif shoot, count rise of flower,count number of flower and number of flower induced. Design of this research is Random block design 1 factor 4 treatment and 3 replication. The concentration of paclobutrazol are 0, 400, 500 , and $600 \mathrm{ppm}$. The result show paclobutrazol $600 \mathrm{ppm}$ able to suppress growth of main spiraling shoot increased $13,32 \mathrm{~cm}$. The average number of secondary spiraling shoot are 3,$84 ; 3,66$ and 3,33 .
\end{abstract}

Keywords: Flowering induction, Mucuna bracteata, Paclobutrazol

\section{PENDAHULUAN}

Mucuna bracteata (MB) merupakan salah satu jenis LCC yang banyak ditanam diperkebunan karena dinilai lebih unggul dari beberapa jenis LCC (Legume Cover Crop) lainnya. Beberapa keunggulan kacangan MB dibandingkan jenis LCC lainnya diantaraya: MB memiliki morfologi daun yang lebih lebar, pertumbuhan yang pesat, tahan terhadap kekeringan dan memiliki biomassa yang lebih tinggi. Pada umur 3 tahun, produksi bahan kering kacangan MB mencapai 12.07 ton/ha di North Labis Estate. Hasil tersebut lebih besar dibandingkan dengan produksi bahan kering Pueraria phaseoloides dan Colopogonium caeruleum sebesar 5.91 ton/ha (Mathew C. 1998). Produksi bahan kering kacanagn MB di Kebun Percobaan Balai Penelitian Sungai Putih pada umur 3 tahun mencapai 10.58 ton/ha (Nugraha PA, Istianto. 2006).

Kacangan MB bermanfaat untuk menekan pertumbuhan gulma dan menambat $\mathrm{N}$ bebas dari udara. Tanaman kacangan MB bisa diperbanyak secara generatif dan vegetatif, jika kondisi lingkungan mendukung. Kacangan MB akan menghasilkan biji jika kacangan tersebut berhasil membentuk bunga sehingga terjadi proses penyerbukan dan pembuahan. Peluang kacangan MB membentuk bunga secara alami sangat kecil terjadi di indonesia, hal ini dikarenakan lingkungan tumbuh yang tidak sesuai dengan habitat alaminya (Harahap IY, et al. 2008)

Pembungaan pada tanaman dapat diinduksi dengan pemberian Paklobutrazol (Wattimena GA. 1998). Paklobutrazol merupakan zat pengatur tumbuh yang tergolong 
retardan. Retardan adalah senyawa organik yang dapat meningkatkan warna hijau daun, mempengaruhi pembungaan, dan menghambat pemanjangan batang (Cathey hm. 1964). Paklobutrazol mengalihkan pertumbuhan vegetatif ke reproduktif tanaman dengan cara menghambat biosintesis giberelin (Darmawan M, et al. 2014). Proses terjadinya pembungaan pada tanaman diatur oleh florigen yang diproduksi oleh daun dan ditranslokasikan ke kuncup untuk memproduksi organ generatif (Ryugo K. 1990).

Faktor yang mempengaruhi terjadinya pembungaan adalah kondisi lingkungan, jumlah nutrisi yang tersedia, dan waktu pemberian paklobutrazol. Pemberian paklobutrazol pada waktu yang tepat akan menurunkan konsentrasi giberelin dalam tanaman. Pengaruh pemberian paklobutrazol pada tanaman juga menyebabkan pembelahan sel menjadi lambat. Tujuan dari penelitian ini adalah untuk melihat pertumbuhan Mucuna bracteata melalui pemberian paklonutrazol dengan sistem tanam vertikal (Rosita SMD, et al. 1993).

\section{METODE PENELITIAN}

\section{Lokasi dan Waktu Penelitian}

Penelitian ini dilaksanakan di kebun percobaan Universitas Labuhanbatu pada bulan Januari sampai Agustus 2020

\section{Persiapan Media Tanam}

Media tanam yang akan digunakan untuk menanam biji kacangan MB adalah sekam dan kompos dengan perbandingan 1:1. Sekam dan kompos diaduk sampai merata, kemudian dimasukkan kedalam polybag berukuran $40 \mathrm{~cm}$ x $50 \mathrm{~cm}$ dan disusun sesuai denah percobaan.

\section{Penanaman Biji Mucuna bracteata}

Tahap pertama sebelum penanaman adalah seleksi biji. Biji kacangan MB direndam dalam air, kemudian dilakukan seleksi biji. Biji kacangan MB yang tenggelam diambil dan dilakukan proses pematahan dormansi dengan teknik skarifikasi dimana bagian titik tumbuh pada biji dilukai agar memudahkan proses penyerapan air. Biji kacangan MB yang telah dilukai kemudian direndam dalam ember berisi air, proses perendaman dilakukan selama 2 jam, setelah itu biji kacangan diletakan dalam lipatan kapas yang telah dibasahi air. Biji kacangan MB yang berhasil berkecaambah kemudian ditanam pada polybag dengan ketentuan 3 biji dalam satu polybag. setelah 5 hari dilkakukan proses seleksi sehingga dalam 1 polybag terdapat satu tanaman dengan kondisi terbaik.

\section{Pemeliharaan}

Pemeliharaan tanaman meliptui pengendalian hama dan penyakit tanaman, penyiangan gulma dan penyiraman. Pengendalian hama dilakukan jika terjadi serangan hama. Pengendalian gulma dilakukan secara manual yaitu mencabut rumput yang ada didalam polybag dan mencangkul gulma sekitar area penelitian.

\section{Aplikasi Paklobutrazol}

Pengenceran larutan paklobutrazol dibuat sesuai konsentrasi perlakuan $(0,400,500$ dan 600) ppm. Paklobutrazol diaplikasikan dengan cara menyemprot larutan paklobutrazol ke seluruh bagian tanaman pada pagi hari sekitar pukul 08.00 wib ketika stomata daun dalam 
keadaan membuka. Pemberian paklobutrazol dilakukan sebanyak tiga kali, yaitu pada saat tanaman berumur 30,40 , dan 50 hari setelah tanam. Setiap perlakuan diulang tiga kali sehingga terdapat 12 satuan percobaan, dan setiap ulangan terdiri dari 10 tanaman sehingga total tanaman terdapat 120 tanaman. Rancangan percobaan dalam penelitian ini adalah Rancangan Acak Kelompok (RAK) satu faktor dengan tiga taraf perlakuan, yaitu 0, 400, 500 dan 600 ppm.

\section{Parameter Penelitian}

1. Panjang Sulur Utama (Primer)

Pengamatan dilakukan dengan mengukur panjang sulur utama (Primer) seminggu setalah aplikasi paklobutrazol pada setiap perlakuan.

2. Jumlah Sulur Samping (Sekunder)

Pengamatan dilakukan dengan menghitung jumlah sulur samping (sekunder) seminggu setalah aplikasi paklobutrazol pada setiap perlakuan.

3. Umur muncul bunga

Pengamatan dilakukan dengan cara mencatat hari keberapa mulai muncul bunga pada setiap perlakuan.

\section{Analisis Data}

Analisis statistik yang digunakan adalah uji F. Apabila berbeda nyata, akan dilanjutkan dengan uji DMRT (Duncan Multiple Range Test) dengan $\alpha=5 \%$.

\section{HASIL DAN PEMBAHASAN}

\section{Panjang Sulur Utama (Primer)}

Mucuna bracteata tergolong tanaman Legume yang mempunyai sulur primer, sulur sekunder dan sulur tersier. Sulur pada tanaman Mucuna terjadi akibat bertambahnya jumlah sel meristem yang mengalami proses pemanjangan sel. Proses pemanjangan sel pada sulur tanaman kacangan terjadi akibat sintesis ZPT giberelin yang terdapat pada sel meristem tanaman Mucuna. Pengaruh paklobutrazol terhadap pertambahan panjang sulur Mucuna bracteata dapat dilihat pada Tabel 1.

Tabel 1. Rerata pertambahan panjang sulur utama $(\mathrm{cm})$ per minggu setelah pemberian paklobutrazol

\begin{tabular}{clll}
\hline $\mathbf{0} \mathbf{~ p p m}$ & $\mathbf{4 0 0} \mathbf{~ p p m}$ & $\mathbf{5 0 0} \mathbf{~ p p m}$ & $\mathbf{6 0 0} \mathbf{~ p p m}$ \\
\hline $50.742 \mathrm{a}$ & $23.94 \mathrm{~b}$ & $17.2 \mathrm{c}$ & $13.32 \mathrm{~d}$ \\
\hline
\end{tabular}

Ket: Angka yang diikuti huruf yang sama pada baris yang sama menunjukkan tidak berbeda nyata pada uji lanjut DMRT taraf 5\%

Berdasarkan Tabel 1 dapat disimpulkan bahwa semakin besar konsentrasi paklobutrazol yang diberikan maka akan sangat mempengaruhi pertambahan panjang sulur utama. Pengamatan akan pertambahan panjang sulur utama dilakukan setiap minggu hingga 12 minggu. Rata- rata pertambahan panjang sulur utama tanaman Mucuna bracteata yang tidak diberikan perlakuan paklobutrazol (kontrol) adalah sebesar 50,74 cm. Perlakuan ini sangat berbeda nyata dengan perlakuan paklobutrazol 400 PPM dimana rata- rata pertambahan panjang sulur adalah $23.94 \mathrm{~cm}$, berbeda nyata dengan perlakuan paklobutraszol 500 PPM dimana rata- rata pertambahan panjang sulur adalah $17.12 \mathrm{~cm}$ dan berbeda nyata 
dengan perlakuan paklobutrazol 600 PPM dimana rata-rata pertambahan panjang sulur adalah $13.32 \mathrm{~cm}$.

Perlakuan pemberian paklobutrazol 600 ppm merupakan perlakuan yang paling berpengaruh nyata terhadap pertambahan panjang sulur utama tanaman $\mathrm{MB}$, karena pada konsentrasi tersebut paklobutrazol menekan pertumbuhan vegetatif Mucuna bracteata hingga memperoleh data pertambahan panjang sulur yang paling pendek dengan rata-rata $13.32 \mathrm{~cm}$. Paklobutrazol tergolong ZPT ratardan yang mempunyai peran dalam menghambat proses pemanjangan sel yang mengakibatkan berkurangnya sintesis ZPT giberelin. Proses sintesis giberelin yang terhambat akan berdampak pada proses pemanjangan sel yang akan mempengaruhi perkembangan sulur terutama pada panjang sulur. Pemeberian paklobutrazol dengan konsentrasi yang tepat akan menghambat sintesis giberelin dalam tubuh tanaman. Pemberian paklobutrazol $6 \mathrm{ml} / \mathrm{l}$ pada kacang tanah dapat menekan pertumbuhan tinggi tanaman dan memperpendek ruas tanaman (Kahar. 2013). Selain rata-rata pertambahan panjang sulur, panjang sulur utama juga diamati untuk melihat respon tanaman Mucuna bracteata terhadap pemberian paklobutrazol (Tabel 2).

Tabel 2. Data panjang sulur utama setelah aplikasi Paklobutrazol

\begin{tabular}{ccccccccc}
\hline \multicolumn{8}{c}{ Pengamatan Panjang Sulur Utama Minggu Ke - } \\
\hline Perlakuan & 5 & 6 & 7 & 8 & 9 & 10 & 11 & 12 \\
\hline 0 PPM & $52.79 \mathrm{a}$ & $96.42 \mathrm{a}$ & $145.68 \mathrm{a}$ & $203.40 \mathrm{a}$ & $261.16 \mathrm{a}$ & $311.70 \mathrm{a}$ & $360.82 \mathrm{a}$ & $407.99 \mathrm{a}$ \\
$\mathbf{4 0 0}$ PPM & $42.74 \mathrm{~b}$ & $70.27 \mathrm{~b}$ & $97.02 \mathrm{~b}$ & $125.15 \mathrm{~b}$ & $150.70 \mathrm{~b}$ & $173.36 \mathrm{~b}$ & $192.32 \mathrm{~b}$ & $210.33 \mathrm{~b}$ \\
$\mathbf{5 0 0}$ PPM & $37.69 \mathrm{c}$ & $59.95 \mathrm{c}$ & $79.95 \mathrm{c}$ & $99.95 \mathrm{c}$ & $117.40 \mathrm{c}$ & $133.25 \mathrm{c}$ & $146.82 \mathrm{c}$ & $157.95 \mathrm{c}$ \\
$\mathbf{6 0 0}$ PPM & $35.68 \mathrm{c}$ & $52.01 \mathrm{~d}$ & $67.95 \mathrm{~d}$ & $82.25 \mathrm{~d}$ & $95.90 \mathrm{~d}$ & $107.73 \mathrm{~d}$ & $118.70 \mathrm{~d}$ & $128.93 \mathrm{~d}$ \\
\hline
\end{tabular}

Ket: Angka yang diikuti huruf yang sama pada baris atau kolom yang sama menunjukkan tidak berbeda nyata pada uji lanjut DMRT taraf 5\%

Berdasarkan Tabel 2, dapat dilihat bahwa setiap minggu sulur MB semakin bertambah panjang. Pemberian paklobutrazol pada konsentrasi dan waktu yang tepat akan menurunkan konsentrasi giberelin dalam tanaman (Yanto R, et al. 2019). Pemberian paklobutrazol pada kacang hijau dengan konsentrasi 100 PPM dapat menekan tinggi tanaman sebesar $30-40 \%$ (Sulandjari, Sumarno. 2008). Kadar giberelin yang menurun dalam tubuh tanaman akan berdampak pada pertumbuhan vegetattif tanaman. Indikasi terganggu pertumbuhan vegetative tanaman adalah dengan berkurangnya penambahan panjang ruas pada tanaman (Denis M, Muhartini S. 2019). Pada tanaman kentang, pemberian paklobutrazol konsentrasi $125 \mathrm{ppm}$ memberikan pengaruh yang nyata terhadap parameter tinggi tanaman (Karmelai N, et al. 2018).

\section{Jumlah Sulur Samping (Sekunder)}

Sulur tanaman Mucuna bracteata mempunyai peran yang penting terhadap proses pertumbuhan fase vaegetatif. Sulur sekunder pada tanaman Mucuna bracteata berfungsi untuk melebarkan jangkauan rentang tanaman, sebagai temapat tumbuhnya organ daun dan bunga, berperan dalam pengambilan unsur hara dalam tanah. Sulur samping tanaman Mucuna bracteata tumbuh pada ruas -ruas sulur utama. Pemberian paklobutrazol dengan berbagai konsentrasi mempengaruhi jumlah sulur samping (Tabel3). 
Copyright@UNISBA Blitar, http://ejournal.unisbablitar.ac.id/index.php/viabel

Kamsia Dorliana Sitanggang, Siti Hartati Yusida Saragih \& Khairul Rizal, 2020. Induksi Pembungaan Mucuna Bracteata Menggunakan Paklobutrazol Dengan Sistem Tanam Vertikal .

Journal Viabel Pertanian. (2020), 14(2) 57-63

Tabel 3. Pengaruh Paklobutrazol terhadap jumlah sulur samping

\begin{tabular}{llll}
\hline \multicolumn{3}{c}{ Perlakuan Paklobutrazol } \\
\hline $\mathbf{0} \mathbf{~ p p m}$ & $\mathbf{4 0 0} \mathbf{~ p p m}$ & $\mathbf{5 0 0} \mathbf{~ p p m}$ & $\mathbf{6 0 0} \mathbf{~ p p m}$ \\
$5.25 \mathrm{a}$ & $3.84 \mathrm{~b}$ & $3.66 \mathrm{~b}$ & $3.33 \mathrm{~b}$ \\
\hline
\end{tabular}

Ket: Angka yang diikuti huruf yang sama pada baris atau kolom yang sama menunjukkan tidak berbeda nyata pada uji lanjut DMRT pada taraf 5\%

Pemberian paklobutrazol dengan konsentrasi 400, 500 dan 600 ppm memberikan pengaruh yang tidak nyata antar perlakuan. Rata-rata jumlah sulur samping MB pada umur 12 minggu dengan konsentrasi 400 ppm yaitu 3.84, sedangkan 500 ppm menghasilkan ratarata jumlah sulur samping 3.66 dan 600 ppm 3.33. Ketiga perlakuan tersebut $(400,500,600)$ ppm berbeda nyata dengan kontrol $(0 \mathrm{ppm})$ dengan rata-rata jumlah sulur samping 5.25. Pemberian paklobutrazol akan menghambat enzim entkaurena oksidase dengan mengubah entkaurena menjadi asam entkaurenoid (Ruminta, et al. 2018). Dengan terhambatnya biosintesis giberelin, maka biosintesis asam absisat (ABA) akan meningkat dan dapat memicu terjadinya pembungaan.

\section{Umur muncul bunga (hari)}

Sampai saat ini masih dilakukan pengamatan terhadap munculnya bunga Mucuna bracteata (Gambar 1). Pemberian paklobutrazol dengan konsentrasi 0,400, 500, dan 600 PPM belum mampu meginduksi munculnya bunga Mucuna bracteata hingga tanaman berumur 8 bulan.

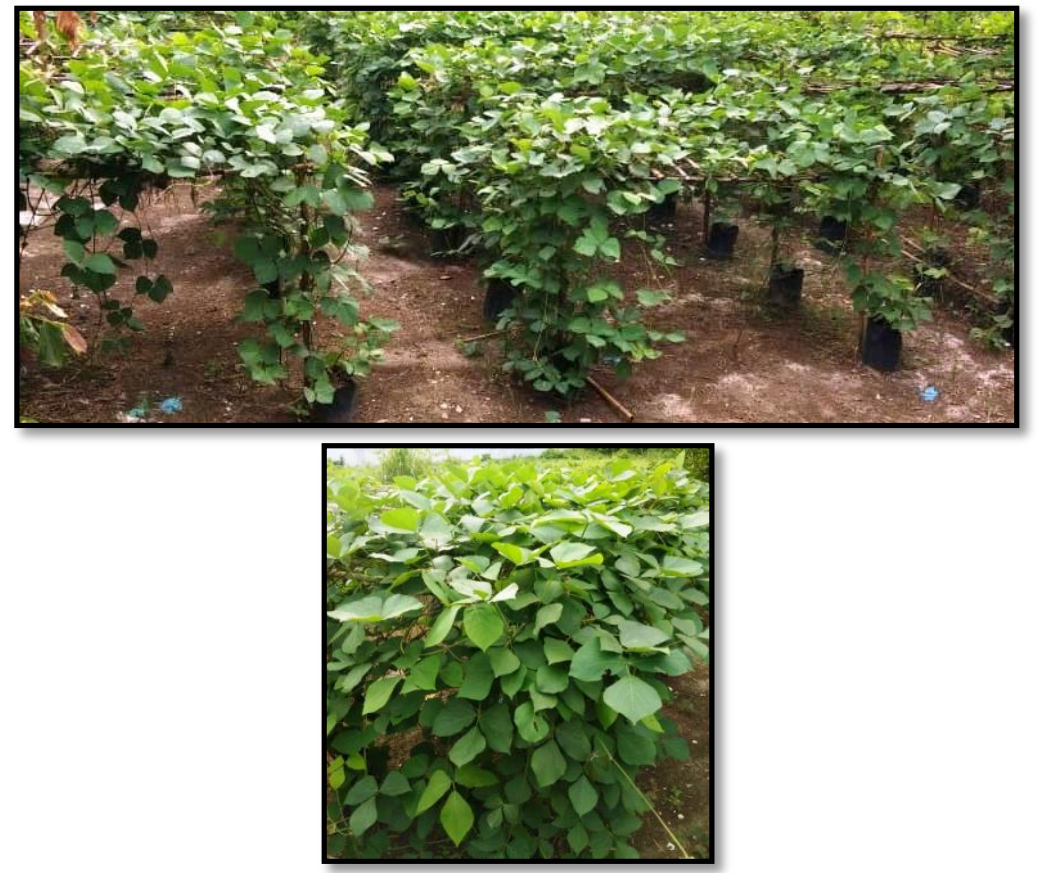

Gambar.1 kondisi umum tanaman Mucuna bracteata dilapangan 
pada Gambar 1 terlihat kondisi tanaman Mucuna bracteata dilapangan setelah beberapa bulan perlakuan paklobutrazol. Pemberian paklobutrazol dapat menghambat panjang sulur tanaman, akan tetapi belum mempu menginduksi bunga pada umur 8 bulan .

\section{KESIMPULAN}

1. Pemberian paklobutrazol dapat menekan pertambahan panjang sulur utama MB (Mucuna bracteata)

2. Pemberian paklobutrazol pada konsentrasi 400, 500, dan 600 ppm pada kacang MB memberikan pengaruh yang tidak beda nyata pada pengamatan jumlah sulur samping

3. Pemberian paklobutrazol pada konsentrasi 400, 500, dan $600 \mathrm{ppm}$ belum mampu menginduksi munculnya bunga Mucuna bracteata pada umur 8 bulan setelah tanam

\section{DAFTAR PUSTAKA}

Cathey hm. 1964. Physiology Of Retarding Chemicals. Annu. Rev. Plant Physol. 15: 272 302

Darmawan M, Poerwanto R, Susanto S. 2014. Aplikasi P rohexadion-Ca, Paclobutrazol, dan Strangulasi Untuk Induksi Pembungaan diluar Musim Pada Tanaman Jeruk Keprok (Citrus reticulate) J.Hort 24(2):133-140

Denis M, Muhartini S. 2019. Pengaruh Jenis Pupuk Kandang dan Konsentrasi Paklobutrazol terhadap Pertumbuhan dan Hasil Kacang Tanah (Arachis hypogaea L). Jurnal Vegetalika 8(2):108-115

Harahap IY, Taufik CH, Simangunsong G, Edy GS, Yusran P, Listia E, Rahutomo S. 2008. Mucuna bracteata Pengembangan dan Pemanfaatannya di Perkebunan Kelapa Sawit. Pusat Penelitian Kelapa Sawit. Buku Saku 28. Hal 46

Kahar. 2013. Pertumbuhan dan Produksi Empat Varietas Kacang dengan Pemberian Paclobutrazol dan Kapur Dolomit. Jurnal Pertanian Terpadu 1(1):70-91

Karmelai N, Sunaryo, Wardiayati T. 2018. Aplikasi Paklobutrazol pada Pertumbuhan dan Hasil Varietas Tanaman Kentang (Solanum tuberosum L) didataran Medium. Jurnal Produksi Tanaman Vol 6(9): 2257-2263

Mathew C. 1998. The Introduction and Establishment of a New Leguminous Cover Plant Mucuna bracteata Under Oil Palm in Malaysia. The Planter: 359-368

Nugraha PA, Istianto. 2006. Dinamika Populasi Mikroba Tanah dibawah Naungan Mucuna bracteata pada Areal Karet Belum Menghasilkan. Pusat Penelitian Karet 2: 114-125

Rosita SMD, Darwati I, Yuliani S. 1993. Pengaruh Paklobutrazol Terhadap Produksi dan Kualitas Rimpang Kunyit. Balai Penelitian Tanaman Rempah dan Obat. Bul. Litro. VIII(2):108-110

Ruminta, Nurmala, Yuwariah, Pratiwi. 2018. Respon Pertumbuhan dan Hasil Tanaman Hanjeli Pada Panen Awal Akibat Pemberian Dosis Pupuk Biosilika dan Paklobutrazol dilahan Kering Jatinangor. Jurnal Kultivasi Vol.17(3): 694-700 
Jurnal Viabel Pertanian Vol. 14 No. 2 November 2020

p-ISSN: 1978-5259 e-ISSN: 2527-3345

Copyright@UNISBA Blitar, http://ejournal.unisbablitar.ac.id/index.php/viabel

Kamsia Dorliana Sitanggang, Siti Hartati Yusida Saragih \& Khairul Rizal, 2020. Induksi Pembungaan Mucuna Bracteata Menggunakan Paklobutrazol Dengan Sistem Tanam Vertikal .

Journal Viabel Pertanian. (2020), 14(2) 57-63

Ryugo K. 1990. Flowering and Fruit Set in Temperate Fruit Trees.Taipei. FFTC. 21-26

Sulandjari, Sumarno. 2008. Pengapuran dan Paklobutrazol Terhadap Pertumbuhan dan Hasil Tanaman Kacang Hijau (Phaseolus radiatus L.) ditanah Berpotensi Masam. Prosiding Seminar Nasional Kacang-kacangan dan Umbi-umbian: 213-219

Yanto R, Yahya S, Lontoh A. 2019. Pengendalian Laju Pertumbuhan Pucuk Tanaman Penutup Tanah Mucuna bracteata dengan Paklobutrazol. Jurnal Agripeat, Vol.2 (1):19

Wattimena GA. 1998. Zat Pengatur Tumbuh Tanaman. Bogor. IPB. 145 hal 